\title{
Kinetics and thermodynamics of enhanced adsorption of E120 dye using activated carbon
}

\author{
Mater H Mahnashi ${ }^{1 *}$, Samer S Abu-Alrub1, Mohammad W Amer ${ }^{2}$, Ali O Alqarni ${ }^{1}$ \\ ${ }^{1}$ Department of Pharmaceutical Chemistry, College of Pharmacy, Najran University, Najran 11001, Kingdom of Saudi Arabia, \\ ${ }^{2}$ Department of Chemistry, School of Science, The University of Jordan, Amman 11942, Jordan \\ *For correspondence: Email: dr.maternahnashi@gmail.com; Tel: +966-17-5428888 ext 1118679
}

\begin{abstract}
Purpose: To study the adsorption of dye (E120) from aqueous solution onto activated carbon. Method: Factors influencing adsorption were examined and optimized. Three adsorption isotherm models (Langmuir, Freundlich and Temkin) were investigated. Agitation time was set at 72 hours, E120 dye concentration at $10-80 \mathrm{mg} / \mathrm{L}, \mathrm{pH}$ at 7 , temperature at $25^{\circ} \mathrm{C}$ and mass at $125 \mathrm{mg}$.

Results: Adsorption of E120 dye onto activated carbon was enhanced by decreasing the mass of activated carbon, $\mathrm{pH}$ and ionic strength of the solution and by increasing the temperature. Under optimal conditions, the maximum adsorption capacity of activated carbon for E120 dye was $10.1 \mathrm{mg} / \mathrm{g}$ at $30^{\circ} \mathrm{C}$. The model parameters were $0.307 \mathrm{~L} / \mathrm{mg}\left(K_{L}\right), 10.1 \mathrm{mg} / \mathrm{g}\left(q_{\mathrm{m}}\right), 0.9491\left(R^{2}\right)$ for the Langmuir isotherm; $2.98(n), 0.445 \mathrm{mg} / \mathrm{g}\left(K_{f}\right)$, and $0.6592\left(R^{2}\right)$ for Freundlich isotherm; and $4.59 \mathrm{mg} / \mathrm{L}(A), 2.23$ $\mathrm{J} / \mathrm{mol}(B)$, and $0.5914\left(R^{2}\right)$ for Temkin isotherm. Thermodynamic studies indicate that the adsorption of E120 dye onto activated carbon is an endothermic process with an adsorption enthalpy $(\Delta H)$ of 8.7 $\mathrm{KJ} / \mathrm{mol}$. The positive values for $\Delta \mathrm{G}$ indicate that adsorption was non-spontaneous. The kinetic study of E120 dye adsorption showed that the adsorption process obeyed pseudo-second order kinetics. Conclusion: Commercially available activated carbon, in terms of its physical and chemical characteristics, is a superior adsorbent to other adsorbents mentioned in the literature for removal of toxic dye E120 from aqueous solutions at a high removal capacity.
\end{abstract}

Keywords: Carmine dye E120, Activated carbon, Thermodynamics, Adsorption isotherm, Kinetic models

\begin{abstract}
This is an Open Access article that uses a fund-ing model which does not charge readers or their institutions for access and distributed under the terms of the Creative Commons Attribution License (http://creativecommons.org/licenses/by/4.0) and the Budapest Open Access Initiative (http://www.budapestopenaccessinitiative.org/read), which permit unrestricted use, distribution, and reproduction in any medium, provided the original work is properly credited.

Tropical Journal of Pharmaceutical Research is indexed by Science Citation Index (SciSearch), Scopus, International Pharmaceutical Abstract, Chemical Abstracts, Embase, Index Copernicus, EBSCO, African Index Medicus, JournalSeek, Journal Citation Reports/Science Edition, Directory of Open Access Journals (DOAJ), African Journal Online, Bioline International, Open-J-Gate and Pharmacy Abstracts
\end{abstract}

\section{INTRODUCTION}

Adsorption is a simple, economic and highly efficient physicochemical process that can be used to optimize the treatment of waste, understand clarification and depollution of industrial liquids [1]. Applications of various adsorption methodologies have expanded rapidly due to rising environmental and quality requirements. They have been used for treating aqueous solutions to remove highly toxic dissolved organic dye components [2]. During the synthesis and application of dyes, large quantities of untreated dyes are discharged into the environment. An example of such dye is carmine (a red azo dye) also known as natural red E120 (Figure 1) [3]. 
$\mathrm{E} 120$ is present as an additive in many products such as artificial flowers, rouge, cosmetics, and some medications [4]. It is also one of the most common dyes used in textile, juice, medical and pharmaceutical applications [5]. Except in low concentrations when used in applications involving human contact or ingestion, E120 is highly toxic causing skin, and eye related diseases, cancer and is neuro-toxic [6]. According to the World Health Organization (WHO), E120 is considered safe at concentrations lower than $0.005 \mathrm{mg} / \mathrm{L}$ [7]. Several methods have been used to remove carmine dye from aqueous solutions including chemical precipitation, ultra-filtration, electrochemical deposition and coagulationflocculation. However, these methods are expensive and have variable efficiency in removing carmine dye from aqueous solutions [8].

Activated carbon is a microporous material used in many applications as adsorbent for removal of dye pollutants from aqueous solution [9]. In this work, the adsorption of carmine dye from aqueous solution using activated carbon was studied as a model system to demonstrate the ability of activated carbon to remove this carcinogenic material from aqueous solution. The effects of different experimental conditions were also investigated.

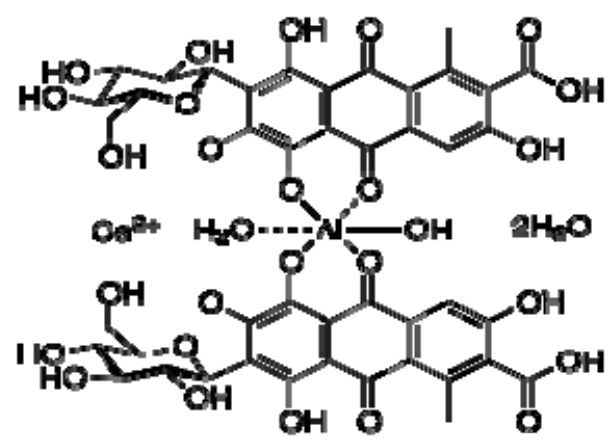

Figure 1: Chemical structure of carmine dye (E 120)

\section{EXPERIMENTAL}

Materials

All reagents used in this work were of analytical grade and were used as received without any further purification. The E120 dye was obtained from Lobal Chemie (India) and activated carbon with particle diameter ranging from 300 to 500 $\mu \mathrm{m}$, surface area of $500-3000 \mathrm{~m}^{2} / \mathrm{g}$ and a total pore volume of $1.4 \mathrm{~cm}^{3} / \mathrm{g}$ was purchased from Nen Tech Ltd (UK). The physiochemical properties of activated carbon were reported by
Al-Degs et al [10]. Activated carbons have a large specific surface area $\left(820 \mathrm{~m}^{2} / \mathrm{g}\right)$ and various bulky functional groups, which give the activated carbon the ability to adsorb considerable amounts of E120 dye. The acidity constant $\left(\mathrm{pK}_{\mathrm{a}}\right)$ of $\mathrm{E} 120$ dye, reported in the literature and not provided by the manufacturer is $5.43[11]$.

\section{Adsorption of E120 dye}

The adsorption properties of the dye were studied using the batch method. A known mass of activated carbon (300 - $500 \mu \mathrm{m}$ diameter) was added to $100 \mathrm{~mL}$ of the dye solution and the mixture was agitated for a known time. The final dye concentration in the solution was measured using a double beam UV-visible spectrophotometer (SP-3000 nano, Optima, Japan). The amount adsorbed by the activated carbon was calculated as the difference between the initial and final dye concentrations. The effects of carbon mass, dye concentration, solution $\mathrm{pH}$, ionic strength, and temperature on E120 dye adsorption were investigated as outlined below.

The concentrations of E120 dye remaining in solution were determined spectrophotometrically, at $290 \mathrm{~nm}$. A linear calibration curve was obtained using a series of standard samples in the concentration range of $10-80.0 \mathrm{mg} / \mathrm{L}$. A linear calibration graph was obtained with correlation coefficient $\left(R^{2}\right)=0.9641$. All experiments were conducted in triplicate. The uncertainty of the measurements was calculated from the standard deviation and estimated to be in all cases less than $1 \%$.

\section{Effect of agitation time on E120 dye}

A mass (125 mg) of activated carbon was added to $100 \mathrm{~mL}$ solutions initially containing $80.0 \mathrm{mg} / \mathrm{L}$ of E120 dye and agitated for times varying from 24 to 120 hours at $25^{\circ} \mathrm{C}$ and $\mathrm{pH} 7$. The concentration of the remaining dye was determined.

\section{Effect of solution $\mathrm{pH}$, ionic strength and mass of adsorbent on E120 dye adsorption}

Carmine dye solution $(100 \mathrm{~mL})$ of initial concentration $80.0 \mathrm{mg} / \mathrm{L}$ was placed in a $100 \mathrm{~mL}$ volumetric flask. The flask was closed and agitated for 72 hours at $25^{\circ} \mathrm{C}$, after which, the concentration of dye remaining was measured. Effect of solution $\mathrm{pH}(1.0,2.0,3.0,7.0,9.0,10.0$ and 11.0) was recorded using an Ezdo $\mathrm{pH}$ meterpp-201 (Taiwan). The mass of activated carbon $(25,50,75,100,125,150,175$ and $200 \mathrm{mg})$ on 
E120 dye adsorption were also recorded. The $\mathrm{pH}$ was monitored in the beginning and at the end of the experiments and was adjusted with either acid or base to the required $\mathrm{pH}$. The effect of ionic strength on the adsorption of the carmine dye was determined by placing $125 \mathrm{mg}$ of activated carbon in $100 \mathrm{~mL}$ of solutions containing $80.0 \mathrm{mg} / \mathrm{L}$ of carmine dye, with different concentrations of sodium chloride $(0.1$ to $0.5 \mathrm{~mol} / \mathrm{L}$ ) and the solutions were agitated for $72 \mathrm{~h}$ at $25^{\circ} \mathrm{C}$ and $\mathrm{pH} 7$. The dye concentration remaining after agitation was determined spectrophotometrically.

\section{Effect of E120 dye concentration}

To investigate the effect of dye concentration, $125 \mathrm{mg}$ of activated carbon was added to 100 $\mathrm{mL}$ of each of eight solutions, all at $\mathrm{pH} 7$ but containing different concentrations of carmine dye $(10.0$ to $80.0 \mathrm{mg} / \mathrm{L})$. The volumetric flasks were agitated for 72 hours at $25^{\circ} \mathrm{C}$ and the remaining dye concentration was determined.

\section{Assessment of adsorption isotherms at different temperatures}

A $125 \mathrm{mg}$ activated carbon was added to each of eight solutions at $\mathrm{pH} 7$ but containing different concentrations of E120 dye (10.0 to $80.0 \mathrm{mg} / \mathrm{L}$ ). The volumetric flasks were agitated in a waterbath shaker at $25^{\circ} \mathrm{C}(298 \mathrm{~K})$ for $72 \mathrm{~h}$. The concentration of dissolved dye remaining was then determined, experiment was repeated at different water-bath temperatures (293 and 313 $\mathrm{K})$. The concentration of adsorbed dye $\left(\mathrm{q}_{\mathrm{e}}, \mathrm{mg} / \mathrm{g}\right)$ was calculated by the difference between the initial $\left(\mathrm{C}_{0}, \mathrm{mg} / \mathrm{L}\right)$ and the equilibrium $\left(\mathrm{C}_{\mathrm{e}}, \mathrm{mg} / \mathrm{L}\right)$ dye concentration. The adsorption of carmine dye was expressed in terms of the distribution coefficient $K_{d}(\mathrm{~L} / \mathrm{g})$ as shown in Eq 2.

$q e=(\mathrm{Co}-\mathrm{Ce}){ }^{*} \mathrm{~V} / \mathrm{m}$

where qe is the concentration of adsorbed dye in $\mathrm{mg} / \mathrm{g}$, Co is the initial concentration $(\mathrm{mg} / \mathrm{L})$, The equilibrium concentration $\mathrm{Ce} \mathrm{mg} / \mathrm{L}, \mathrm{V}$ is the volume of the solution in $L$, and $m$ is the mass of adsorbent $(\mathrm{g})$.

$(\mathrm{Kd})=\mathrm{qe} / \mathrm{Ce}$

\section{RESULTS}

The E120 dye contains a large number of functional groups. The physiochemical properties of E120 dye play a significant role in the effect of $\mathrm{pH}$ and ionic strength on the adsorption of E120 dye by activated carbon.

\section{Effect of agitation time on E120 dye}

Figure 2 shows that the $\mathrm{K}_{d}$ value for adsorption of carmine dye increased with time. A short contact time is desirable for economic reasons. $\mathrm{K}_{\mathrm{d}}$ greater than $1 \mathrm{~L} / \mathrm{g}$ is generally considered acceptable [12]. A contact time of $72 \mathrm{~h}$, giving a $\mathrm{K}_{\mathrm{d}}$ of $1.3 \mathrm{~L} / \mathrm{g}$, was chosen for subsequent experiments. It was found that 72 hours were sufficient to obtain a reasonable value of distribution coefficient $\left(\mathrm{K}_{\mathrm{d}}\right)$ and this agitation time was used in subsequent experiments.

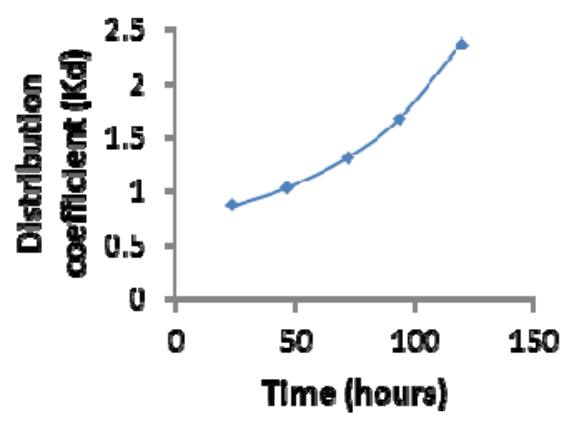

Figure 2: Effect of agitation time on E120 dye adsorption onto activated carbon

\section{Effect of solution $\mathrm{pH}$, ionic strength and mass of adsorbent on carmine dye}

As shown in Figure $3, \mathrm{~K}_{\mathrm{d}}$ increased with acidity of the solution, from $0.27 \mathrm{~L} / \mathrm{g}$ at $\mathrm{pH} 11$ to $2.96 \mathrm{~L} / \mathrm{g}$ at $\mathrm{pH}$ 1. The adsorption of E120 dye on the activated carbon was strongly influenced by the $\mathrm{pH}$ of the solution. At low $\mathrm{pH}$, the oxygen functional groups on the dye is protonated, as the pKa was 5.3 and hydrogen bonds are formed between dye molecules and functional groups on activated carbon [13]. As the $\mathrm{pH}$ increases, the dye molecules become negatively charged and gets repelled by the negatively-charged activated carbon surface [14]. Furthermore, the increasing number of $\mathrm{OH}^{-}$ions are strongly adsorbed and competes with dye molecules for adsorption sites [14]. Hydrophobic interactions between the aromatic part of the dye molecule (Figure 1) and the hydrophobic parts of the activated carbon surface are responsible for such binding of the dye molecules to the activated carbon [13].

As shown in Figure 5, distribution coefficient $\mathrm{K}_{\mathrm{d}}$ value decreased from $3.71 \mathrm{~L} / \mathrm{g}$ at $0.1 \mathrm{M} \mathrm{NaCl}$ to $0.23 \mathrm{~L} / \mathrm{g}$ at $0.5 \mathrm{M} \mathrm{NaCl}$. Thus, another one of the factors that play a role in adsorption of E120 dye from solution is the salt level in the solution. Adsorption of E120 dye decreased with increased $\mathrm{NaCl}$ concentration. The salt ions screen the surface of the activated carbon from the dye molecules and so reduce any attractive 
electrostatic interaction between the dye and the activated carbon [13]. The added ions also compete with dye molecules for adsorption sites on the active carbon surface. Similar trend was reported by Boumediene et al [15]. They found that as the ionic strength increased, the adsorption capacity of the studied dye decreased. This was attributed to the competition between the ions and the dye on the adsorbent surface.

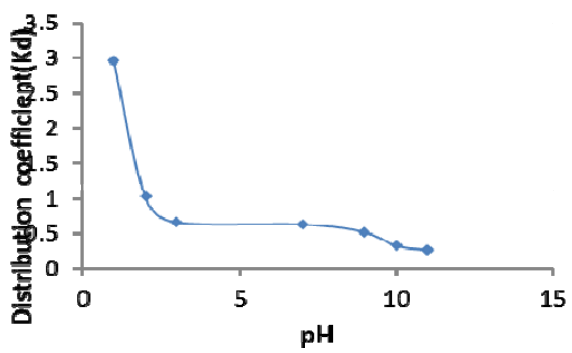

Figure 3: Effect of $\mathrm{pH}$ on E120 dye adsorption onto activated carbon

Removal of E120 dye from solution also depends on the amount of activated carbon per $100 \mathrm{ml}$ of solution. As shown in Figure $4, \mathrm{~K}_{\mathrm{d}}$ decreased when the mass of activated carbon increased. However, $\mathrm{K}_{d}$ values showed only small changes for masses greater than $125 \mathrm{mg}(0.05 \mathrm{~L} / \mathrm{g})$.

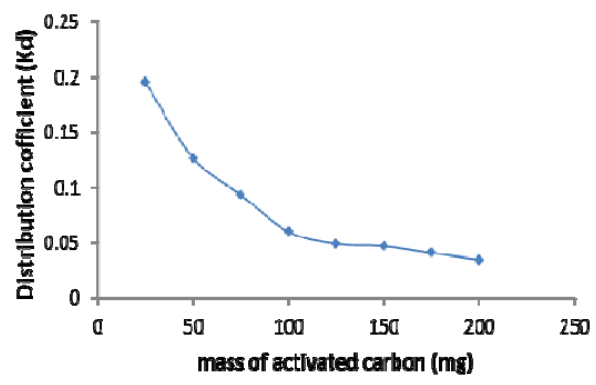

Figure 4: Effect of mass of activated carbon on E120 dye adsorption

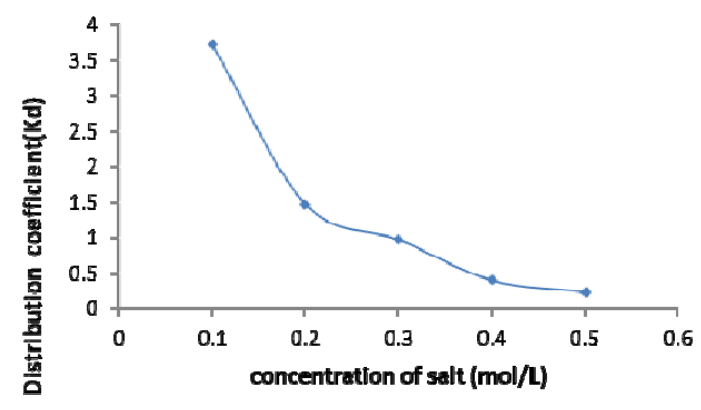

Figure 5: Effect of ionic strength on E120 dye adsorption

\section{Effect of E120 dye concentration}

The effect of concentration of E120 dye on its adsorption was investigated in the concentration range $10.0-80.0 \mathrm{mg} / \mathrm{L}$, at $\mathrm{pH} 7,25^{\circ} \mathrm{C}, 72 \mathrm{~h}$ of shaking and activated carbon amount of $125 \mathrm{mg}$. As shown in Figure 6, the distribution coefficient $\left(K_{d}\right)$ value increased when the concentration increased $\left(K_{d}\right.$ value increased from $0.49 \mathrm{~L} / \mathrm{g}$ at $10 \mathrm{mg} / \mathrm{L}$ to $1.36 \mathrm{~L} / \mathrm{g}$ at $80 \mathrm{mg} / \mathrm{L})$ which might be due to increase in the available sites for adsorption of E120 dye. Kd changed to only a small extent with concentration above $60 \mathrm{mg} / \mathrm{L}$ which might be due to limited available sites of the activated carbon dose for the removal of E120 dye at higher concentration. Therefore 80 $\mathrm{mg} / \mathrm{L}$ was selected as the initial concentration for investigating the effects of other variables.

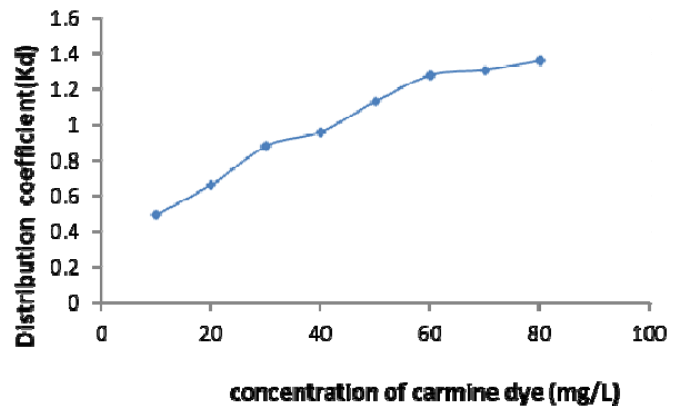

Figure 6: Effect of E120 dye concentration adsorption onto activated carbon

\section{Adsorption isotherms}

The effects of temperature on adsorption of E120 dye was measured using varying concentrations at different temperatures and the results are shown in Figure 7. The distribution coefficient of E120 dye increased with increasing temperature suggesting that this was an endothermic process. Higher temperatures may have led to the creation of new active sites on the activated carbon and thus permitted more adsorption of the dye, as suggested by Al-Degs et al [13].

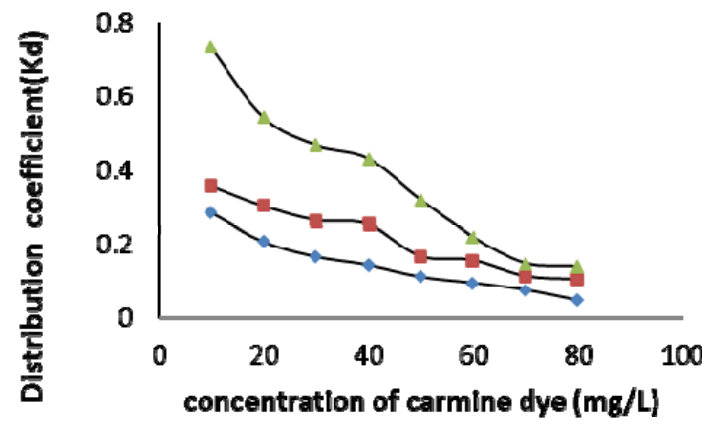

Figure 7: Effect of temperature on E120 dye adsorption onto activated carbon at $293 \mathrm{~K}(-\downarrow-), 298 \mathrm{~K}$ (-m-), and $303 \mathrm{~K}(-\mathbf{\Delta}-)$

Trop J Pharm Res, March 2021; 20(3): 588 
Langmuir, Temkin and Freundlich models were used to determine the maximum adsorption capacity of activated carbon for E120 dye. The fits of the adsorption data to the three models are presented in Figure 8. As shown in Table 1, the Langmuir model was the best-fit isotherm model for E120 dye adsorption into activated carbon which indicated that all the adsorption sites are equivalent and therefore homogenous. The $\mathrm{R}^{2}$ values for the Freundlich and Temkin isothermfits indicated that these models are less suitable for the current system. The values of $n$ obtained for the Freundlich model to the E120 dye adsorption process over the tested concentration range (10 to $80 \mathrm{mg} / \mathrm{L}$ ) showed that the surface of activated carbon was reasonably homogeneous, in $293-303 \mathrm{~K}$ as far as the dye molecules were concerned [16]. The values of Temkin isotherm model $A$ and $B$ indicated that the heat of sorption results from physical interaction between the activated carbon and E120 dye (Table 1).

\section{Thermodynamic parameters of carmine dye adsorption}

The values of enthalpy $\Delta \mathrm{H}(\mathrm{KJ} / \mathrm{mol})$ and entropy $\Delta S(\mathrm{~J} / \mathrm{mol} . \mathrm{K})$ for the adsorption of E120 dye into activated carbon were calculated as in Eq 3.

In $K_{d}=\Delta S^{\circ} / R-\Delta H^{\circ} / R T$

$\mathrm{R}$ represents the gas constant $(8.314 \mathrm{~J} / \mathrm{mol} . \mathrm{K}), \mathrm{T}$ is the absolute temperature and is measured by (Kelvin), while $\mathrm{K}_{d}$ is the distribution coefficient. $\Delta \mathrm{H}^{\circ}$ and $\Delta \mathrm{S}^{\circ}$ can be calculated from the slope and intercept of the plot of In $K_{d}$ versus $1 / T$, respectively. As shown in Table 2, the values of $\Delta \mathrm{H}^{\circ}(\mathrm{kJ} / \mathrm{mol})$ and $\Delta \mathrm{S}^{\circ}(\mathrm{J} / \mathrm{mol} . \mathrm{K})$ were 8.7 and 27.8 , respectively. The positive value of $\Delta \mathrm{H}^{\circ}$ indicated that the E120 dye adsorption onto active carbons was endothermic. The energy of dehydration (liberation of the previously adsorbed water) is higher than the energy of adsorption (bond formation between E120 dye and surface of activated carbons)[9]. The enthalpy of adsorption of organic molecules from aqueous solution on activated carbon range from $8-65 \mathrm{~kJ} / \mathrm{mol}$ [10]. The negative sign of entropy indicated the decreased randomness at the solid-liquid interface during E120 dye adsorption on activated carbon. The decreased randomness was due to increased liberation of the previously adsorbed water molecules upon dye adsorption [17]. The positive sign of free energy values $(\Delta G)$ indicated that the adsorption process is not spontaneous. The free energy values $(\Delta G)$ increased from $16.86 \mathrm{KJ} / \mathrm{mol}$ at $293 \mathrm{~K}$ to 17.14 $\mathrm{KJ} / \mathrm{mol}$ at $303 \mathrm{~K}$ again indicating that the adsorption of E120 dye onto activated carbon was endothermic.
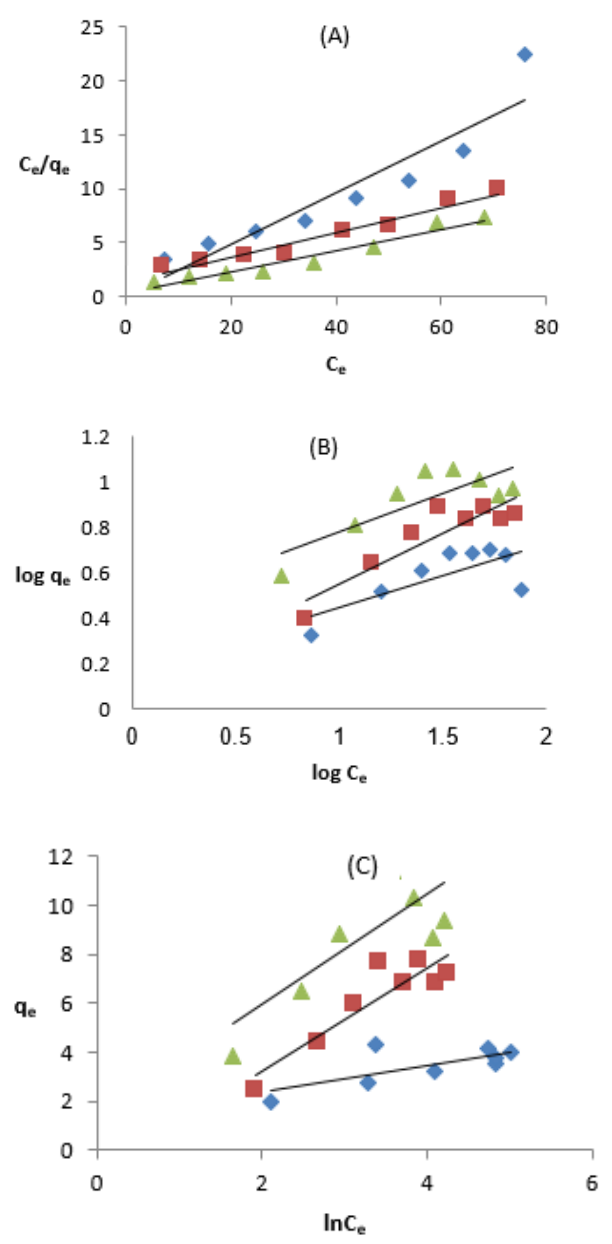

Figure 8: Langmuir (A), Freundlich (B), and Temkin (C) models of carmine dye adsorption onto activated

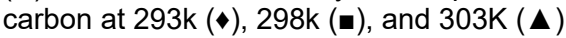

Table 1: Langmuir, Freundlich and Temkin parameters

\begin{tabular}{|c|c|c|c|c|c|c|c|c|c|c|c|}
\hline \multicolumn{4}{|c|}{ Langmuir } & \multicolumn{4}{|c|}{ Freundlich } & \multicolumn{4}{|c|}{ Temkin } \\
\hline$T(K)$ & $R^{2}$ & $\begin{array}{c}q_{m} \\
(m q / q)\end{array}$ & $\begin{array}{c}K_{L} \\
(L / m q)\end{array}$ & $T(K)$ & $R^{2}$ & $\begin{array}{c}K_{f} \\
(m g / q)\end{array}$ & $n$ & $T(K)$ & $R^{2}$ & $\begin{array}{c}A \\
(L / q)\end{array}$ & $\begin{array}{c}B \\
(J / m o l)\end{array}$ \\
\hline 293 & 0.8705 & 4.18 & 2.30 & 293 & 0.5656 & 0.1574 & 3.48 & 293 & 0.5165 & 2.08 & 0.5462 \\
\hline 298 & 0.9563 & 8.73 & 0.08 & 298 & 0.8194 & 0.1026 & 2.23 & 298 & 0.8216 & 0.33 & 2.1203 \\
\hline 303 & 0.9491 & 10.11 & 0.31 & 303 & 0.6592 & 0.4453 & 2.98 & 303 & 0.5419 & 4.59 & 2.2321 \\
\hline
\end{tabular}




\section{Adsorption kinetic models}

Kinetics models were investigated to evaluate the adsorption of E120 dye into activated carbon. The pseudo-first order and pseudo-second order were used to evaluate the experimental data.

\section{Pseudo first-order}

Values of $k_{1}$ and $q_{e}(\mathrm{mg} / \mathrm{g})$ were calculated by plotting a graph of log $\left(q_{e}-q_{t}\right)$ versus't' (hours) as in Eq 4.

$\log \left[q_{e}-q_{t}\right]=\log \left[q_{e}\right]-\left[k_{1} / 2.303\right] t$

where qe and qt are the adsorption capacity at equilibrium and at time $\mathrm{t}$, respectively $(\mathrm{mg} / \mathrm{g})$. K1 is the pseudo first-order rate constant. The rate constants $\left(k_{1}\right)$ and qe can be calculated from the slope and intercept of the linear plot, respectively. As shown in Table 3, the value of experimental qe' value $(\mathrm{mg} / \mathrm{g})$ does not agree with the calculated 'qe' (mg/g) plot. Also, Figure 9 showed that $R^{2}=0.9946$ indicates that the first order Kinetic model does not fit with the adsorption of E120 dye into activated carbon.

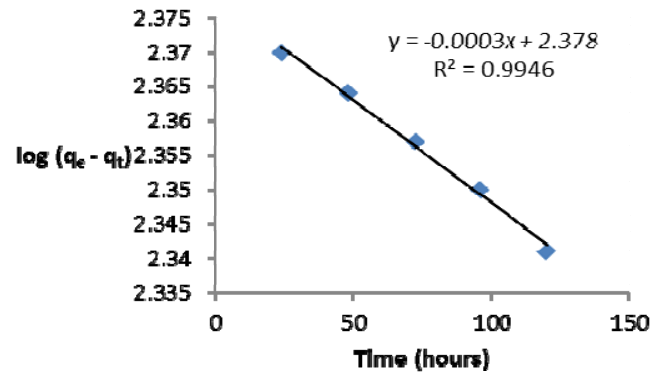

Figure 9: Pseudo-first- order kinetics for E120 dye adsorption onto activated carbons

\section{Pseudo-second-order kinetic model}

Pseudo-second-order kinetics must be studied if the adsorption involves chemical interactions/bonding between the adsorbent and adsorbate (Eq 5).

$t / q_{t}=1 / k_{2} q_{e}{ }^{2}+1 / q_{e} t$

where $q_{e}, q_{t}$, and $t$, were explained above, $k_{2}$ is the rate constant of pseudo second-order kinetic adsorption [g/mg.min]. Values of $\mathrm{k}_{2}$ and $\mathrm{q}_{\mathrm{e}}(\mathrm{mg} / \mathrm{g})$ were calculated by plotting $t / q_{e}$ versus ' $t$ ' (hours) which will give a linear plot if the model is valid (Figure 10). The rate constants $\left(k_{2}\right)$ and $q_{e}$ can be calculated from the slope and intercept of the linear plot, respectively, (Table 2). The value of experimental qe' $(\mathrm{mg} / \mathrm{g})$ was in agreement with the calculated ' $q_{e}$ ' $(\mathrm{mg} / \mathrm{g})$. Figure 10 showed that $\mathrm{R}^{2}=0.9885$ indicating that pseudo-second order kinetic model is the suitable kinetic model for E120 into activated carbon.

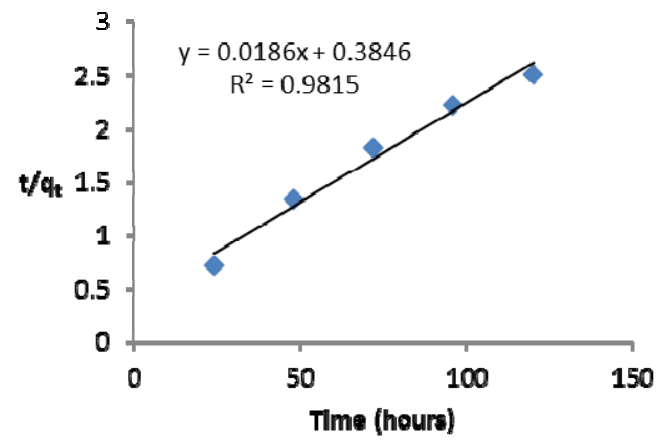

Figure 10: Pseudo second- order kinetics for E120 dye adsorption onto activated carbons

\section{Comparison of carmine dye adsorption with various adsorbents}

The adsorptive capacities of the adsorbents used in this work have been compared with those of others reported in the literature and the values of adsorption capacity are presented in Table 4 . The adsorption capacity $\left(q_{m}\right)$ is used as comparative parameter. The $q_{m}$ value obtained in this study agrees with most previous studies but higher than most of them, which indicated that the activated carbon used in this study easily removed the E120 dye from solutions.

\section{DISCUSSION}

Adsorption isotherms of the $\mathrm{E} 120$ dye on activated carbon was better fitted of the equilibrium adsorption data to the Langmuir isotherm model than the Freundlich and Temkin isotherm models and gave a maximum adsorption capacity of $4.18 \mathrm{mg} / \mathrm{g}$ at $293 \mathrm{~K}$ which increased to $10.11 \mathrm{mg} / \mathrm{g}$ at $303 \mathrm{~K}$ and $\mathrm{pH}=7$.

Table 3: Parameters for various kinetic models

\begin{tabular}{|c|c|c|c|c|c|c|}
\hline \multirow{2}{*}{$\begin{array}{l}\text { Initial dye } \\
\text { conc. (mg/L) }\end{array}$} & \multicolumn{3}{|c|}{ Pseudo-First-order } & \multicolumn{3}{|c|}{ Pseudo-Second-order } \\
\hline & $k_{1}\left(\min ^{-1}\right)$ & $\begin{array}{c}\text { Calculated } \\
q_{e}(m g / g)\end{array}$ & $R^{2}$ & $k_{2}(g / m g . \min )$ & $\begin{array}{c}\text { Calculated } \\
q_{e}(\mathrm{mg} / \mathrm{g})\end{array}$ & $R^{2}$ \\
\hline 80 & 5.48 & 0.99 & 0.9946 & $8.99 \times 10^{-4}$ & 53.76 & 0.9815 \\
\hline
\end{tabular}


Table 4: Comparison of adsorption capacity of different adsorbents for the adsorption of carmine dye

\begin{tabular}{|c|c|c|}
\hline Adsorbent & $\begin{array}{c}\text { Adsorption } \\
\text { capacity } \\
q_{m}(m g / g) \\
\end{array}$ & Reference \\
\hline Fly Ash (FA) & 1.48 & [18] \\
\hline $\begin{array}{l}\text { Synthesized zeolite } \\
(\mathrm{ZM})\end{array}$ & 1.23 & [18] \\
\hline $\begin{array}{l}\text { Apricot Stone } \\
\text { Active Carbon }\end{array}$ & 552.5 & [4] \\
\hline $\begin{array}{l}\text { Cola nut shells } \\
\text { (treated with } \\
\mathrm{H}_{3} \mathrm{PO}_{4} \text { ) }\end{array}$ & 9.997 & [4] \\
\hline $\begin{array}{l}\text { Active carbon } \\
\text { (treated with } \\
\mathrm{H}_{3} \mathrm{PO}_{4} \text { ) }\end{array}$ & 5.861 & [4] \\
\hline $\begin{array}{l}\text { Active carbon } \\
\text { (treated with } \mathrm{KOH} \text { ) }\end{array}$ & 12.093 & [4] \\
\hline Calcium hydroxide & 4.865 & [12] \\
\hline Activated Carbon & 10.11 & This work \\
\hline
\end{tabular}

Adsorption of E120 dye onto activated carbon was non-spontaneous (positive $\Delta G$ ) and endothermic (positive $\Delta \mathrm{H}$ ) in nature at the examined temperature range.

The negative entropy $(\Delta S)$ state clearly that the decreased randomness at the solid-solution interface during E120 dye adsorption onto the activated carbon. Adsorption of E120 dye onto activated carbon obeyed pseudo second-order kinetic model.

\section{CONCLUSION}

This study demonstrates the applicability of activated carbon as a sustainable adsorbent for the removal of E120 dye from aqueous solution. The adsorption could be described by Langmuir, Freundlich and Tempkin isotherm with a maximum adsorption capacity of $4.18 \mathrm{mg} / \mathrm{g}$.

The thermodynamic investigation showed that adsorption of E120 dye onto activated carbon was non-spontaneous (positive $\Delta \mathrm{G}$ ) and endothermic (positive $\Delta H$ ) in nature at the examined temperature range.

\section{DECLARATIONS}

\section{Acknowledgement}

This project was funded by the Deanship of Scientific Research at Najran University, Kingdom of Saudi Arabia.

\section{Conflict of interest}

No conflict of interest is associated with this work.

\section{Contribution of authors}

We declare that this work was done by the authors named in this article and all liabilities pertaining to claims relating to the content of this article will be borne by the authors. Mater $\mathrm{H}$ Mahnashi: Conceptualization, Project administration, Writing - original draft, Writing - review \& editing, Formal analysis, Visualization, Validation. Samer S Abu-Alrub: and Mohammad W Amer conceived this work, did the laboratory work and data analysis as well as the manuscript writing which was read and approved by all authors for publication. Ali $\mathrm{O}$ Alqarni was involved in data analysis, writing of the manuscript and final review of the manuscript before submission for publication.

\section{Open Access}

This is an Open Access article that uses a funding model which does not charge readers or their institutions for access and distributed under the terms of the Creative Commons Attribution License (http://creativecommons.org/licenses/by/ 4.0) and the Budapest Open Access Initiative (http://www.budapestopenaccessinitiative.org/rea d), which permit unrestricted use, distribution, and reproduction in any medium, provided the original work is properly credited.

\section{REFERENCES}

1. Amer MW, Ahmad RA, Awwad AM. Biosorption of Cu (II), $\mathrm{Ni}$ (II), Zn (II) and $\mathrm{Pb}$ (II) ions from aqueous solution by Sophora japonica pods powder. 2015. 6(1): 75.

2. Abu-Alrub SS, Amer MW, Alkahtani SA. Adsorption of the Sudan dye (III) in methanol using activated carbon. Journal: Journal of Advances in Chemistry. 10(10).

3. Dapson R, Frank M, Penny PD, Kiernan Dr Ja. Revised procedures for the certification of carmine (C.I. 75470, Natural red 4) as a biological stain. Biotechnic \& Histochemistry, 2007. 82(1): 15.

4. Odogu AN, Daouda K, Desire BBP, Nsami NJ. Removal of indigo carmine dye (ic) by batch adsorption method onto dried cola nut shells and its active carbon from aqueous medium. 2016. 5(3): 887.

5. Craik JD, Khan $D$, Afifi $R$. The Safety of Intravenous Indigo Carmine to Assess Ureteric Patency During Transvaginal Uterosacral Suspension of the Vaginal Vault. Female Pelvic Medicine \& Reconstructive Surgery, 2009. 15(1): 15.

6. Barka N, Assabbane A, Nounah A, Ichou YA. Photocatalytic degradation of indigo carmine in aqueous solution by TiO2-coated non-woven fibres. Journal of Hazardous Materials, 2008. 152(3):1059.

Trop J Pharm Res, March 2021; 20(3): 591 
7. Patel H, Vashi RT. Treatment of Textile Wastewater by Adsorption and Coagulation. E-Journal of Chemistry, 2010. 7(4):1476.

8. Bernal M, Romero R, Roa G, Barrera-Díaz C. Ozonation of Indigo Carmine Catalyzed with Fe-Pillared Clay. International Journal of Photoenergy, 2013. 2013: 7.

9. Alkahtani SA, Abu-Alrub SS, Mahmoud AM. ADSORPTION OF FOOD COLORING ALLURA RED DYE (E129) FROM AQUEOUS SOLUTIONS USING ACTIVATED CARBON. 2017, 2017. 3(1):10.

10. Al-Degs YS, El-Barghouthi MI, El-Sheikh AH. Effect of solution $\mathrm{pH}$, ionic strength, and temperature on adsorption behavior of reactive dyes on activated carbon. Dyes and Pigments, 2008. 77(1): 23.

11. Rasima JP, Berglund KA, Blanchard GJ. A Molecular Lock-and-Key Approach To Detecting Solution Phase Self-Assembly. A Fluorescence and Absorption Study of Carminic Acid in Aqueous Glucose Solutions. The Journal of Physical Chemistry, 1996. 100(17): 7229.

12. Ramesh TN, Kirana DV, Ashwini A. Calcium hydroxide as low-cost adsorbent for the effective removal of indigo carmine dye in water. Journal of Saudi Chemical Society, 2015. 21(2): 171.

13. Al-Degs YS, Abu-El-Halawa R, Abu-Alrub SS. Analyzing adsorption data of erythrosine dye using principal component analysis. Chemical Engineering Journal, 2012. 191: 194.

14. Sun D, Zhang Z, Wang M, Wu Y. Adsorption of Reactive Dyes on Activated Carbon Developed from \&lt;i\&gt;Enteromorpha prolifera\&lt;/i\&gt. American Journal of Analytical Chemistry, 2013. Vol.04No.07:10.

15. Boumediene M, George B, Molina St, Merlin A. Effects of $\mathrm{pH}$ and ionic strength on methylene blue removal from synthetic aqueous solutions by sorption onto orange peel and desorption study. J. Mater. Environ. Sci., 2018. 9(6):11.

16. Haghseresht F, Lu GQ. Adsorption Characteristics of Phenolic Compounds onto Coal-Reject-Derived Adsorbents. Energy \& Fuels, 1998. 12(6): 1107.

17. Guo Y, Zhao J, Zhang H, Yang S, Qi J, Wang Z, Xu H. Use of rice husk-based porous carbon for adsorption of Rhodamine $B$ from aqueous solutions. Dyes and Pigments, 2005. 66(2): 128.

18. Carvalho de, Fungaro $D$, Magdalena $C$, Cunico $P$. Adsorption of indigo carmine from aqueous solution using coal fly ash and zeolite from fly ash. Journal of Radioanalytical and Nuclear Chemistry, 2011. 289(2): 626. 